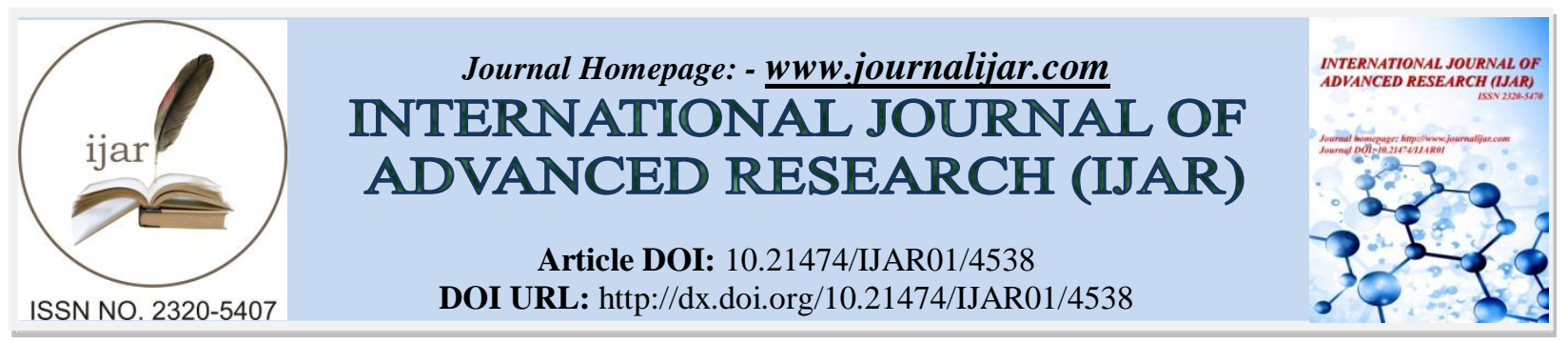

RESEARCH ARTICLE

\title{
REVIEW: SMOKING DURING PREGNANCY MENACING TO BABY.
}

Archana Joon ${ }^{1}$ and Rekha Jalandra ${ }^{2}$.

1. Former M.Sc Student, Department of Zoology, MDU Rohtak, Haryana, India.

2. Assistant Professor, Department of Zoology, Hindu Girls College, Sonepat, Haryana, India.

\section{Manuscript Info}

Manuscript History

Received: 19 April 2017

Final Accepted: 21 May 2017

Published: June 2017

Key words:-

Pregnancy, Maternal Smoking, Cigarette

Smoke, Vasoconstrictors

\section{Abstract}

Smoking during pregnancy can lead to a plethora of health risks to both the mother and the foetus. A number of studies have shown that tobacco use is a significant factor in miscarriage among pregnant smokers, and that it contributes to a number of other threats to the health of the foetus. Moderate-to-heavy maternal smoking is responsible for an average reduction in body weight of in infants whose mothers smoked during pregnancy. Smoking during pregnancy has also been implicated in neurological as well as maturational modifications observed in infants born to smoking mothers. Metabolites of cigarette smoke cross the placenta, passing from mother to foetus, and act as vasoconstrictors that reduce uterine blood flow. Maternal smoking, therefore, places the foetus under chronic hypoxic stress, and hence contributes to restriction in weight gain, reduced length and many more diseases and defects. Babies whose mothers smoke during pregnancy are at higher risk of SIDS, having weaker lungs and having a low birth weight. Low birth weight babies are at greater risk of death and are more vulnerable to infection, breathing difficulties and long-term health problems in adulthood. Passive smoking can also affect a pregnant woman and her child. The more cigarettes smoked during pregnancy, the greater the risk of complications and low birth weight.

Copy Right, IJAR, 2017,. All rights reserved.

\section{Introduction:-}

One of the most important things an expecting mother can do for her unborn baby is to quit smoking. Research over the years has shown that smoking during pregnancy can have a significant amount of negative effects on the developing foetus. Cigarette tobacco contains approximately 2,500 chemicals that could harm an unborn baby. Nicotine, tar, and carbon monoxide are the most harmful to the foetus. When an expecting mother inhales tobacco smoke from a cigarette, some of the chemicals are exhaled immediately and leave the body, but others stay in the body and make their way into the placenta. The unborn child, as well as inhaling the mainstream smoke that the mother breathes in from the cigarette, which stays in her body, it may also inhale any second-hand smoke that is in the air. A variety of adverse pregnancy outcomes are linked with cigarette smoking before and during pregnancy. Maternal prenatal cigarette smoke interrupts the equilibrium among the oxidant and antioxidant system, has negative effect on both mother and foetus, which causes many diseases in the unborn child. Prenatal tobacco exposure (PTE) affected speech processing, levels of irritability and hypertonicity, attention levels, ability to self-regulate, need to be handled, and response to novelty preference in infants. It is estimated that 15 to $25 \%$ of women smoke during 
pregnancy [1,2,3]. Worldwide, 250 million women use tobacco daily, according to statistics from the 14th World Conference on Tobacco or Health held in 2009 in Mumbai.

\section{Smoking Mothers And Unborn Childs:-}

The fact that smoking cigarettes throughout pregnancy is important avoidable cause of adverse pregnancy outcomes, resulting in serious short- and long-term negative impacts for the mother and the foetus has been proven by many different studies $[4,5,6,7]$. It can be considered as the first major environmental risk factor that can be confronted by the unborn in the undeveloped world. Exposure to cigarette smoke is considered to be amongst the most harmful. The side effects of combustion are believed to impose more harm to the foetus than the nicotine itself, but due to the complexity and number of dangerous substances it is unknown which toxic effect is caused by exactly which product [8]. This is mainly notable as the majority of the smoking-induced harm for the unborn foetus is lasting. Even today modern medicine offers very little treatments for the long-term negative consequences of being exposed to smoke during pregnancy [9]. According to a 2010 study from the USA, one of the most significant behavior changes a future mother can make is the complete cessation of smoking in pregnancy, with numerous health benefits for both the woman and her offspring [10]. Prenatal exposure to nicotine may lead to deregulation in neurodevelopment and can indicate higher risk for psychiatric problems, including substance abuse. Among women in India, smokeless tobacco has been demonstrated to constitute more than $95 \%$ of the total tobacco consumption, thereby by far surpassing smoking as the primary source of nicotine during gestation [11]. In the Mumbai Cohort study [12], 58\% of 59,527 lower-middle and lower-class women age 35 years and old reported current tobacco use, virtually all of which was smokeless. In some regions, e.g. Sweden, smoking has decreased at a higher rate and is now below $10 \%$ [13]. This decrease is however often coupled to a simultaneous increase in the use of smokeless tobacco, resulting in virtually unaltered levels of nicotine exposure for the foetus [13].

\section{Element of Tobacco smoke:-}

There are many ingredients in tobacco smoke which are harmful to an individual's health in different ways. The smoke that burns off the end of a cigarette or cigar actually contains more harmful substances (tar, carbon monoxide, nicotine, and others) than the smoke inhaled by the smoker. Some of the ingredients are tar, carbon monoxide, nicotine and other chemicals and additives such as ammonia, arsenic (a poison used in insecticides and weed killers), benzene, hydrogen cyanide and many others. Millions of pregnant women use smokeless tobacco, predominantly in Africa and Asia [14] but also in Scandinavia [15]. These women are not exposed to the combustion products in tobacco smoke (e.g. carbon monoxide and cyanide) that may contribute to foetal hypoxia and reduced birthweight, but as nicotine levels may be very high the foetal exposure to nicotine may be unaltered or even increased.

\section{Consequences of Smoking during pregnancy:-}

Most people know that smoking causes cancer, heart disease, and other major health problems. Tobacco is the most commonly used substance during pregnancy [16]: up to $25 \%$ of pregnant women smoke [17,18].Smoking during pregnancy causes additional health problems, including premature birth, certain birth defects, babies born too small, babies who die before they can be born at all. Smoking causes shortage of oxygen which in turn has devastating effects on baby's growth and development. On average, smoking during pregnancy doubles the chances that a baby will be born too early or weigh less than $51 / 2$ pounds at birth. Smoking during pregnancy also doubles the risk of stillbirth and risk of delivering a pre-term baby. Several studies agree that smoking women were more likely to deliver a pre term baby with the total rate of delivering a pre-term baby increasing up to 33\% [19,20,21,22]. Cigarettes are legal poisons, which damage not only the health of the mother, but endanger the health of the unborn child as well. These smoking-induced damages for the unborn offspring evident themselves at various times in life, some being clearly visible from birth on, others becoming manifest only in the following generation. These diseases have one thing in common: the vast majority of them are permanent and for most only a very limited range of causal treatment exists. For many of these diseases only symptomatic therapeutic treatments are available at best [9]. Maternal smoking during pregnancy is associated with several adverse developmental outcomes in the offspring. A large number of studies confirm that maternal tobacco smoking during pregnancy adversely affects pre- and postnatal growth and increases the risk of fetal mortality [23,24,25], morbidity [26,27], cognitive development [28,29], and behavior of children and adolescents [30,31].

\section{Weight and size:-}

While some women may welcome the prospect of delivering a smaller baby, stunting a baby's growth in the womb can have negative consequences that last a lifetime. The baby also might be considerably light in weight. Intrauterine growth retardation of the unborn child is the most important smoking-induced pathology [9]. A dose- 
response relationship between maternal smoking rates and low birth weight (potentially associated with lower cognitive ability) and spontaneous abortion is consistently found.

\section{Body and Lungs:-}

Undersize babies tend to have underdeveloped bodies. Their lungs may not be ready to work on their own, which means they may spend their first days or weeks attached to a respirator. After they're breathing on their own (or even if they did from the start), these babies may have continuing breathing problems - because of delayed lung development or other adverse effects of nicotine. When the mother smokes, there is a reduced supply of oxygen, due to the increase of nicotine and carbon monoxide in the mother's bloodstream. This means that there is less oxygen available to the baby. Tar deposits on the lungs can cause lung diseases. Children whose mothers smoked during pregnancy are especially vulnerable to asthma, and have double or even triple the risk of sudden infant death syndrome (SIDS). The association between the risk for Sudden Infant Death Syndrome (SIDS) and maternal smoking during pregnancy is well established and smoking is the strongest risk factor for SIDS displaying a definite dose-response relationship. Maternal smoking of more than 20 cigarettes per day increases the relative risk for SIDS five-fold [32].

\section{Heart:-}

A baby whose mother smoked in the first trimester of pregnancy is more likely to have a heart defect at birth.In a U.S. Centers for Disease Control and Prevention (CDC) study published in February 2011, these babies' risk of having certain types of congenital heart defects was 20 to 70 percent higher than it was for babies whose moms didn't smoke. The defects included those that obstruct the flow of blood from the right side of the heart into the lungs (right ventricular outflow tract obstructions) and openings between the upper chambers of the heart (atrial septal defects). Carbon monoxide and other chemicals reduce the oxygen carrying capacity of the blood and play a significant role in the development of smoking-related heart disease and damaged various parts of the body such as blood vessels. Nicotine causes blood vessels to constrict, raises blood pressure, increases heart rate and increases the hearts demand for oxygen and it stimulates then nervous system. The risk of fetal congenital heart defects has been shown by two studies to be at least partially linked to exposure to maternal smoking in early pregnancy or to be directly linked to maternal smoking during pregnancy for some specific subtypes [33,34]. A number of studies have investigated the cardiovascular effects of nicotine during pregnancy [35].

\section{Brain function:-}

Smoking during pregnancy can have lifelong effects on your baby's brain. Children of pregnant smokers are especially likely to have learning disorders, behavioral problems, and relatively low IQs. Nicotine crosses the placenta and is concentrated in the fetal tissue. The direct effects of nicotine predict deficits in growth and neural development, which have long-term effects on brain function, cognition, and behavior [36].

\section{Placenta:-}

According to a study published in the journal PLoS One, nicotine can cause contractions in the fallopian tubes. These contractions can prevent an embryo from passing through. One possible result of this is an ectopic pregnancy. Indirectly, nicotine affects size through placental pathology [7].The placenta is the "lifeline" structure that forms during pregnancy to provide the foetus with nutrients and oxygen. Smoking is a major risk factor for several complications linked to the placenta. One such problem is placenta abruption. This is a condition in which the placenta separates from the uterus before childbirth. Placenta abruption can cause severe bleeding and threaten the life of both the mother and the baby. There's no surgery or treatment to reattach it. Smoking is also a risk factor for placenta previa. During pregnancy, the placenta normally grows in the uterus towards the top of the womb. This leaves the cervix open for delivery. Placenta previa is when the placenta stays in the lower part of the uterus, partially or fully covering the cervix. The placenta often tears, which causes excessive bleeding and depriving the foetus of vital nutrients and oxygen. Smoking during pregnancy reduces the amount of oxygen that crosses the placenta to the baby and it also leads to an increased risk of miscarriages, premature births and sudden infant death syndromes (SIDS) (cot deaths). The placenta is an important source of hormones, pro-oxidant agents and antioxidant enzymes and in a physiological pregnancy this vital organ is able to control lipid peroxidation [37]. Several studies concluded that maternal prenatal cigarette smoking disturbs the equilibrium among the oxidant and antioxidant system, thus causing additional oxidative stress and augmenting lipid peroxidation. Smoking during pregnancy increases the free radical damage to the unborn fetus as well as to the mother $[37,38,39]$. 


\section{Other Defects:-}

Not only can smoking cause considerable damage to the unborn baby, but it could affect the baby later in life. Smoking increases the chances of the baby having birth defects. Smoking during pregnancy raises the risk of your baby being born with birth defects. The most common types of problems are congenital heart defects and problems with the structure of the heart. Other health issues that have been linked to smoking while pregnant include cleft lip and cleft palate. The baby also might be considerably light in weight. If certain genetic susceptibilities are present, the harmful effects of smoking during pregnancy are multiplied [40,41,42].

\section{Conclusion:-}

Smoking cigarettes has a negative impact on the maternal and foetal genetic and cellular level; the increase in foetal heart defects due to smoking during pregnancy. Maternal cigarette smoking during pregnancy is likely to affect foetal kidney development leading to kidney disease and hypertension later in adult life. Smoking and pregnancy is significantly linked with a decrease in pulmonary function in addition to asthma and respiratory infections in offspring later in life. Additionally, an elevated risk for various gastrointestinal defects is observed in offspring of smokers. Multiple studies agree that maternal smoking during pregnancy harms linear growth, promotes increased Body Mass Index (BMI) in children and increases the risk for obesity in childhood and adult life [43,44,45,46]. It is important that pregnant women are warned of the detrimental effects of smoking, and encouraged to abstain for healthy foetal development.

\section{References:-}

1. Ananth C.V., Savitz D.A., Luther E.R. Maternal cigarette smoking as a risk factor for placental abruption, placenta previa, and uteine bleeding in pregnancy. Am. J. Epidemiol. 1996;144:881-889.

2. Nelson EA, Taylor BJ. International Child Care Practices Study infant sleep position and parental smoking. Early Hum. Dev. 2001;64:7-20.

3. Owen L, Penn G. Smoking and pregnancy. A survey of knowledge attitudes and behaviour Health Development Agency London. 1999.

4. Higgins S.T., Washio Y., Heil S.H., Solomon L.J., Gaalema D.E., Higgins T.M., Bernstein I.M. Financial incentives for smoking cessation among pregnant and newly postpartum women. Prev. Med. 2011;55:S33-S40.

5. Bickerstaff M., Beckmann M., Gibbons K., Flenady V. Recent cessation of smoking and its effect on pregnancy outcomes. Aust. N. Z. J. Obstet. Gynaecol. 2012;52:54-58.

6. El-Mohandes A.A., El-Khorazaty M.N., Kiely M., Gantz M.G. Smoking cessation and relapse among pregnant African-American smokers in Washington, DC. Matern. Child Health J. 2011;15:S96-S105.

7. Dudenhausen J.W. Rauchen in der Schwangerschaft-Häufigkeit. Urban und Vogel; Munich, Germany: 2009. (in German)

8. Knut-Olaf H., Groneberg D. Tabakabhängigkeit-Gesundheitliche Schäden durch das Rauchen. Springer Verlag; Berlin, Germany: 2008. (in German)

9. Thäle V., Schlitt A. Effects of alcohol and smoking in pregnancy. Internist. 2011;52:1185-1190.

10. Simmons V.N., Cruz L.M., Brandon T.H., Quinn G.P. Translation and adaptation of smoking relapseprevention materials for pregnant and postpartum Hispanic women. J. Health Commun. 2011;16:90-107.

11. Gupta P. Smokeless tobacco use in India. Smokeless Tobacco or Health: An International Perspective., Bethesda, MD: US Department of Health and Human Services, Public Health Service, National Institutes of Health. 1992. pp. 19-25.

12. Gupta P. Socio-demographic characteristics of tobacco use among 99,598 individuals in Bombay, India using hand-held computers. Tob. Control. 1996;5:114-120.

13. Socialstyrelsen, Tobacco habits in Sweden. Swedish Medical Board. 2006

14. Idris AM, Ibrahim SO, Vasstrand EN, Johannessen AC, Lillehaug JR, Magnusson B, Wallstrom M, Hirsch JM, Nilsen R. The Swedish snus and the Sudanese toombak: are they different? Oral Oncol. 1998;34:558-66.

15. NSDUH Report. Office of Applied Studies, Substance Abuse and Mental Health Services Administrations (SAMSA) US Department of Health and Human Services; 2005. Substance use during pregnancy: 2002 and 2003.

16. Arria A, Derauf C, Lagasse L, et al. Methamphetamine and other substance use during pregnancy: preliminary estimates from the infant development, environment, and lifestyle (IDEAL) study. Matern Child Health J. 2006;10:293-302.

17. Centers for Disease Control and Prevention. Prevalence of selected maternal behaviors and experiences, pregnancy risk assessment monitoring system. MMWR. 2002;51(SS2) 
18. Ahluwawalia I.B., Grummer-Strawn L., Scanlon K.S. Exposure to environmental tobacco smoke and birth outcome: Increased effects on pregnant women aged 30 years and older. Am. J. Epidemiol. 1997;146:42-47.

19. Ananth C.V., Savitz D.A., Luther E.R. Maternal cigarette smoking as a risk factor for placental abruption, placenta previa, and uteine bleeding in pregnancy. Am. J. Epidemiol. 1996;144:881-889.

20. Cnattingius S., Axelsson O., Eklund G., Lindmark G. Smoking, maternal age, and fetal growth. Obstet. Gynecol. 1985;66:449-452.

21. Wang X., Tager I.B., Van Vunakis H., Speizer F.E., Hanrahan J.P. Maternal smoking during pregnancy, urine cotinine concentrations, and birth outcomes. A prospective cohort study. Int. J. Epidemiol. 1997;26:978-988.

22. Abel EL. Smoking and pregnancy. J. Psychoactive Drugs. 1984;16:327-38.

23. Butler NR, Goldstein H, Ross EM. Cigarette smoking in pregnancy: its influence on birth weight and perinatal mortality. Br. Med. J. 1972;2:127-30.

24. Kleinman JC, Pierre MB Jr, Madans JH, Land GH, Schramm WF. The effects of maternal smoking on fetal and infant mortality. Am. J. Epidemiol. 1988;127:274-82.

25. Habek D, Habek JC, Ivanisevic M, Djelmis J. Fetal tobacco syndrome and perinatal outcome. Fetal Diagn. Ther. 2002;17:367-71.

26. Thorngren-Jerneck K, Herbst A. Low 5-minute Apgar score a population-based register study of 1 million term births. Obstet. Gynecol. 2001;98:65-70.

27. Bauman KE, Flewelling RL, LaPrelle J. Parental cigarette smoking and cognitive performance of children. Health Psychol. 1991;10:282-8.

28. Fried PA, O'Connell CM, Watkinson B. 60- and 72-month follow-up of children prenatally exposed to marijuana, cigarettes and alcohol cognitive and language assessment. J. Dev. Behav. Pediatr. 1992;13:383-91.

29. Wasserman RC, Kelleher KJ, Bocian A, Baker A, Childs GE, Indacochea F, Stulp C, Gardner WP. Identification of attentional and hyperactivity problems in primary care: a report from pediatric research in office settings and the ambulatory sentinel practice network. Pediatrics. 1999;103:E38.

30. Weissman MM, Warner V, Wickramaratne PJ, Kandel DB. Maternal smoking during pregnancy and psychopathology in offspring followed to adulthood. J. Am. Acad. Child Adolesc. Psychiatry. 1999;38:892-9.

31. Milerad J, Sundell H. Nicotine exposure and the risk of SIDS. Acta Paediatr. Suppl. 1993;82(Suppl. 389):70-2.

32. Allina J., Grabowski J., Doherty-Lyons S., Fiel M.I., Jackson C.E., Zelikoff J.T., Odin J.A. Maternal allergy acts synergistically with cigarette smoke exposure during pregnancy to induce hepatic fibrosis in adult male offspring. J. Immunotoxicol. 2011;8:258-264.

33. Chehab G., El-Rassi I., Adhami A., Chokor I., Chatila F., Haddad W., Saliba Z. Parental smoking during early pregnancy and congenital heart defects. J. Med. Liban. 2012;60:14-18.

34. Dempsey DA, Benowitz NL. Risks and benefits of nicotine to aid smoking cessation in pregnancy. Drug Saf. 2001;24:277-322.

35. Marie D. Cornelius and Nancy L. Day. Developmental consequences of prenatal tobacco exposure Curr Opin Neurol. 2009 Apr; 22(2): 121-125

36. Dittrich R., Schibel A., Hoffmann I., Mueller A., Beckmann M.W., Cupisti S. Influence of maternal smoking during pregnancy on oxidant status in amniotic fluid. In Vivo. 2012;26:813-818.

37. Chelchowska M., Ambroszkiewicz J., Gajewska J., Laskowska-Klita T., Leibschang J. The effect of tobacco smoking during pregnancy on plasma oxidant and antioxidant status in mother and newborn. Eur. J. Obstet. Gynecol. Reprod. Biol. 2011;155:132-136.

38. Sahinli A.S., Marakoğlu K., Kiyici A. Evaluation of the levels of oxidative stress factors and ischemia modified albumin in the cord blood of smoker and non-smoker pregnant women. J. Matern. Fetal Neonatal Med. 2012;25:1064-1068.

39. Prins J.R., Hylkema M.N., Erwich J.J., Huitema S., Dekkema G.J., Dijkstra F.E., Faas M.M., Melgert B.N. Smoking during pregnancy influences the maternal immune response in mice and humans. Am. J. Obstet. Gynecol. 2012;207:76.e1-76.e14.

40. Tyrrell J., Huikari V., Christie J.T., Cavadino A., Bakker R., Brion M.J., Geller F., Paternoster L., Myhre R., Potter C., et al. Genetic variation in the 15q25 nicotinic acetylcholine receptor gene cluster (CHRNA5CHRNA3-CHRNB4) interacts with maternal self-reported smoking status during pregnancy to influence birth weight. Hum. Mol. Genet. 2012;21:5344-5358.

41. Joubert B.R., Håberg S.E., Nilsen R.M., Wang X., Vollset S.E., Murphy S.K., Huang Z., Hoyo C., Midttun Ø., Cupul-Uicab L.A., et al. 450K Epigenome-Wide Scan Identifies Differential DNA Methylation in Newborns Related to Maternal Smoking During Pregnancy. Environ. Health Perspect. 2012;120:1425-1431.

42. Idris AM, Ibrahim SO, Vasstrand EN, Johannessen AC, Lillehaug JR, Magnusson B, Wallstrom M, Hirsch JM, Nilsen R. The Swedish snus and the Sudanese toombak: are they different? Oral Oncol. 1998;34:558-66. 
43. Matijasevich A., Brion M.J., Menezes A.M., Barros A.J., Santos I.S., Barros F.C. Maternal smoking during pregnancy and offspring growth in childhood: 1993 and 2004 Pelotas cohort studies. Arch. Dis. Child. 2011;96:519-525.

44. Mamun A.A., O’Callaghan M.J., Williams G.M., Najman J.M. Maternal smoking during pregnancy predicts adult offspring cardiovascular risk factors - evidence from a community-based large birth cohort study. PLoS One. 2012;7:e41106.

45. Raum E., Küpper-Nybelen J., Lamerz A., Hebebrand J., Herpertz-Dahlmann B., Brenner H. Tobacco smoke exposure before, during, and after pregnancy and risk of overweight at age 6. Obesity. 2011;19:2411-2417.

46. Durmus B., Kruithof C.J., Gillman M.H., Willemsen S.P., Hofman A., Raat H., Eilers P.H., Steegers E.A., Jaddoe V.W. Parental smoking during pregnancy, early growth, and risk of obesity in preschool children: The Generation R Study. Am. J. Clin. Nutr. 2011;94:164-171. 